\title{
STRENGTHENING SOCIAL JUSTICE IN INFORMAL DISPUTE RESOLUTION PROCESSES THROUGH CULTURAL COMPETENCE
}

\section{Gemma Smyth*}

Professor Voyvodic's call for cultural competence as an ethical requirement challenges perceptions of the legal profession as inherently and necessarily morally neutral. While lawyers wrestle with the boundaries of ethical mandates, alternative dispute resolution practitioners have adopted their own codes of ethics following very much in the path of the law. Although expanding dispute resolution options for disputants, many theorists have warned of the potential of informalism to undermine natural justice principals. I will argue that the choice to omit any explicit commitment to a "social justice ethic" leaves the practice of ADR vulnerable to these decades-old arguments that informalism erodes protections for marginalized populations. As such, I will argue that mediators must call for an explicit social justice mandate in their codes of conduct, training and practices to cement the place of informal processes as equitable - not just efficient - options for settlement. In doing so, informal processes, particularly mediation, may increase discourse in civil society about human rights, thus strengthening their congruence with lived realities of citizens.

L'appel que fait la professeure Voyvodic en faveur de compétence culturelle comme exigence éthique lance un défi aux avocats de considérer la compétence culturelle comme étant centrale à leur rôle professionnel, et conteste les suppositions de neutralité morale qui sont centrales à la pratique juridique traditionnelle. Pendant que les avocats débattent les frontières de mandats éthiques, ceux et celles qui sintéressent au règlement extrajudiciaire de conflits (REC) ont adopté leurs propres codes de déontologie qui, suivant de près les sentiers du droit, omettent généralement toute mention de justice sociale, de compétence culturelle ou de droits de la personne. À mon avis, le choix d'omettre un engagement explicite envers la compétence culturelle et la justice sociale expose la pratique du REC aux arguments vieux de plusieurs décennies que l'informalisme ronge les protections pour les populations marginales. Ainsi je soutiendrai que les médiateurs doivent exiger un mandat explicite de justice sociale dans leurs codes de déontologie, leur formation et leurs pratiques afin de cimenter la place des processus informels comme alternatives équitables - et non

* Gemma Smyth is currently Assistant Professor and Academic Clinic Director at University of Windsor's Faculty of Law. She was formerly Director of University of Windsor Mediation Services. The author wishes to thank Adam Vasey, and Professors Reem Bahdi and Julie Macfarlane for their helpful suggestions. The author also wishes to acknowledge the important work of the late Professor Rose Voyvodic in advancing ethical and reflective approaches to practice in poverty law and beyond. 
seulement efficaces - de règlement de conflits. De cette façon, les processus informels, surtout la médiation, pourraient devenir des lieux importants de discours au sujet des droits de la personne qui reflètent mieux les défis envisagés par les membres les plus vulnérables de la société.

\section{INTRODUCTION}

Professor Voyvodic wrote and taught about the value of cultural competence to ethical lawyering. ${ }^{1}$ Her work challenges lawyers to practice self-reflectively, to acknowledge systemic power and privilege, and to keep the needs of the client primary. While Alternative Dispute Resolution (ADR) ${ }^{2}$ scholarship and practice has traditionally encouraged self-reflection and examined "imbalances of power," including the power of the mediator, ${ }^{3}$ it has also been critiqued for undermining principles of natural justice and perpetuating discrimination. ${ }^{4}$ Particularly as mediation becomes increasingly professionalized, the ethical codes which guide mediation practice must reflect a serious formal and substantive commitment to social justice. ${ }^{5}$ Specifically, ethical codes of dispute resolution

1 See especially Rose Voyvodic, "Advancing the Justice Ethic Through Cultural Competence" (2005), online: Ontario Justice Education Network <http://www.ojen.ca/eng/resources/ show.cfm?id=108>; Rose Voyvodic, “'Change is Pain:' Ethical Legal Discourse and Cultural Competence” (2004) 14 Wash. U.J.L. \& Pol'y 101; Rose Voyvodic, "Lawyers Meet the Social Context" (2005) 84:3 Can. Bar Rev. 563.

2 For the purposes of this paper, ADR (or "DR") processes include negotiation, mediation, medarb, arbitration, and other sub-genres that exclude judicial adjudication. These processes are also referred to as informal dispute resolution processes, although arbitration, with its use of evidentiary processes and loose use of precedent, more closely resembles adjudication. It should be noted that ADR practice is quite diverse in its composition; practitioners and theorists may be trained as lawyers, social workers, criminologists, sociologists, anthropologists, or - as is the case in many mediation clinics - they may be experts or leaders in their own communities. The professionalization of mediation in North America, Australia, New Zealand and many European countries, however, has led most ADR organizations to require their mediators to have academic training of some sort, combined with formal ADR training. This paper does not purport to address traditional dispute resolution processes particular to cultural groups including shari'a, or Aboriginal, or panchayat systems.

3 See e.g. Deborah Kolb, When Talk Works (San Francisco: Jossey-Bass, 1996) at 479, Bernard Mayer, The Dynamics of Conflict Resolution (San Francisco: Jossey-Bass, 2000); Genevieve Chornenki, "Exchanging 'Power Over' for 'Power With"” in Julie Macfarlane, ed., Rethinking Disputes: The Mediation Alternative (Toronto: Emond Montgomery, 1997) 164.

4 See e.g. Martha Bailey, "Unpacking the 'Rational Alternative:' A Critical Review of Family Mediation Movement Claims" (1989) 8 Can. J. Fam. L. 61; Howard Gadlin, "Conflict Resolution, Cultural Differences and the Culture of Racism” (1994) 10 Negotiation Journal 33; Annette Townley, “The Invisible-Ism” (1992) 9:4 Mediation Quarterly 397; B. Mayer, The Dynamics of Power in Mediation and Negotiation (1987) 16 Mediation Quarterly 75; Gary LaFree, “The Effects of Participant's Ethnicity and Gender on Monetary Outcomes in Monetary Outcomes in Mediated and Adjudicated Civil Cases” (1996) 30 Law \& Soc'y Rev. 767; Sarah Cobb, "Empowerment and Mediation: A Narrative Perspective" (July 1993) Negotiation Journal 245. Isabelle Gunning, "Diversity Issues in Mediation: Controlling Negative Cultural Myths" (1995) 1 J. Disp. Resol. 55 at 69.

5 The definition of social justice is contentious. Michael Reisch attributes this to a deep division over whether the proper domain of social justice is class/economics or identity/recognition in "Social 
must explicitly protect and promote social justice and cultural competence as central values of ADR practice. ${ }^{6}$ This paper looks to examples of other professional codes, particularly that of the Canadian Association of Social Workers, ${ }^{7}$ to guide recommendations for ethical codes that incorporate cultural competence and commitment to social justice within ADR. Using these guidelines and relying on Professor Voyvodic's conception of cultural competence, this paper then addresses ADR's potential to provide a space for more robust dialogue around human rights, cultural competence, and social justice at a local level. ${ }^{8}$

\section{DEFINING CULTURAL COMPETENCE AND SOCIAL JUSTICE}

Although the term "competence" on its face refers to skills, Professor Voyvodic regarded cultural competence as requiring a more nuanced understanding of systemic discrimination and the ability to engage in deep self reflection. She described the "characteristics of the culturally competent lawyer" as

- KNOWLEDGE: about how 'cultural' differences affect client experiences of the legal process as well as their interactions with lawyers;

- SKILLS: through self-monitoring, to identify how assumptions and stereotypes influence his/her own thinking and behaviour, as well as the thinking and behaviour of others, and to work to lessen the effect of these influences;

Justice and Multiculturalism: Persistent Tensions in the History of U.S. Social Welfare and Social Work" (2007) 1:1 Studies in Social Justice 67-92. Almost all schools of thought agree that social justice at its minimum includes human rights and state protection of its citizens, particularly the most vulnerable. While there have been debates about the extent of state intervention in securing social justice, the involvement of politics and systemic analysis is a mark of modern definitions of social justice. For a more thorough historical analysis of the development of the term "social justice" see Janine Brodie, "Reforming Social Justice in Neoliberal Times" (2007) 1:2 Studies in Social Justice 93-104. For the purposes of this paper, I will include respect for international human rights principles as expressed in the Universal Declaration of Human Rights, infra note 8 as well as attention to the lived realities of inequality as fundamental to conceptions of social-justice-in-action.

6 Dispute resolution occurs at many levels of formality, including what Deborah Kolb \& Judith Williams call "Everyday Negotiation" in their book of the same title, (San Francisco: Jossey-Bass, 2003) to more formalized and regulated mediation processes. For the purposes of this paper, I will focus on mediation that occurs pursuant to a code of conduct or ethical code in a North American context.

7 Canadian Association of Social Workers, Code of Ethics and Guidelines for Ethical Practice (2005), online: Canadian Association of Social Workers <http://www.casw-acts.ca/>.

8 The importance of local-level discussion of human rights is echoed in the United Nations' $60^{\text {th }}$ anniversary celebration of the Universal Declaration of Human Rights (1948-2008). See especially the Office of the High Commissioner for Human Rights, "Launch of a Yearlong Celebration of the $60^{\text {th }}$ Anniversary of the UDHR," online: United Nations Human Rights <http://www.ohchr. org/EN/UDHR/Documents/60UDHR/HRD07infokitEN.pdf>. See also Sally Engle Merry, Human Rights and Gender Violence: Translating International Law into Local Justice (Chicago: University of Chicago Press, 2006) for a discussion of the complex interactions between negotiation and international human rights. Both underline the importance of 'on-the-ground' understandings and discussions of human rights; I argue later that mediation is a key site to communicate these fundamental issues. 
- ATTITUDE: awareness of him/herself as a cultural being and of the harmful effects of power and privilege; and the willingness and desire to practice competently in the pursuit of justice. ${ }^{?}$

Requiring understanding and awareness of culture, particularly how culture and power interact and potentially reify one another, is inextricably linked to notions of social justice. An understanding of culture and power is also crucial from a dispute resolution process design perspective. If the dispute resolution design process does not directly identify power and unmask cultural assumptions, then mediators are not likely to help the parties to a dispute achieve successful resolution. We have come to understand this fact quite clearly at the University of Windsor Mediation Services (Mediation Services) which offers mediation, facilitation and conflict resolution training to communities within the Windsor area. ${ }^{10}$ I will draw on these examples to illustrate the importance of cultural competence for successful dispute resolution and to demonstrate that cultural competence should be considered integral to mediation practice.

Recently, Mediation Services was approached by a local Tenants Association that needed to draft a new Constitution but could not develop consensus from its members to finalize the text. Mediation Services was engaged to facilitate this process. This facilitation process initially proved difficult for the mediators who could not pinpoint the true source of conflict. ${ }^{11}$ The Tenants Association members had stated their primary problem was resolving conflict about forming a new Constitution. It soon became clear, however, that one of the true underlying issues was their inability to garner sufficient support and participation from the broader circle of tenants themselves. When the mediators considered the composition of the members of this Tenants Association and the building, it became obvious that the all-male Executive did not include females or members of the South Asian or African-Canadian communities; important constituencies in terms of numbers and influence in the building. When speaking with various women and racialized persons in the building, the mediators found troubled personal histories between tenants. For example, most women were intimidated and as such did not attend meetings or vote. The men had made remarks to the women that made them feel very unwelcomed. But, the men themselves had not connected their behaviour and remarks to their inability to recruit interested tenants to the Tenants Association. Most of the men viewed their comments as reflective of their generation and considered their behaviour and treatment of the women acceptable. The Tenants Association also did not consider it important to include ethnically diverse members of the community. When seen through a broader frame that considers systemic power imbalances and is at-

9 "Lawyers Meet the Social Context" (2006) 84:3 Can. Bar Rev. 563 at 581-582.

10 Mediation Services is a project of the Faculty of Law at the University of Windsor in which law and social work students intern for an academic credit under the supervision of professional mediators. More information about Mediation Services can be found online: University of Windsor <wwww.uwindsor.ca/mediation>.

11 Facts and names have been altered to protect the identities of the participants. 
tentive to cultural differences, the Tenants Association's problems needed to be framed differently. While drafting a Constitution was a tangible way to address problems in the building, the more difficult issue was that of human rights and social justice. Drafting the Constitution was simply the site where the real issues - human rights and social justice - surfaced. Having developed an appreciation for the issues, the mediators had to determine how to address the parties and help guide them to a resolution.

After consulting with all the parties, the mediators brought the parties together to discuss the larger issues facing the Tenants Association. Confronted with the tenants' feelings during mediation, the issues of sexism and racism arose quickly and powerfully. Rather than ignoring or sidelining these issues, the mediators framed the issues very specifically and sought direct participation from all affected parties. The mediators needed to generate understanding but not necessarily acceptance of the behaviour at issue. While the men's explanation of their conduct was valuable to the other tenants, it was also important that the issues be framed in a way that their behaviour not be excused, and that anger be given space for full expression. ${ }^{12}$ It was also necessary that positive steps be taken to remedy the current problems and prevent future issues from escalating. During the mediation session, the parties were willing to engage in discussion about various markers of inequality including the impact of culture, religion, sexuality, and age on life and decision-making within the building. While some of the members remained sceptical, there was a palpable and dramatic change in mutual understanding during the session. In the next election, caucasian and black women were voted into the executive of the Association and changes were made to the Constitution to include greater representation from women and other marginalized tenants in the building. Since this time, Mediation Services has also been engaged in work with building management on issues of ageism and worked with the tenants and other organizations on accessibility of services.

Professor Voyvodic's work on cultural competence informed our approach to these mediation sessions in important ways. All mediators at Mediation Services are trained in reflective practitioner and cultural competence models which emphasize understanding of how and why a formal process such as drafting a Constitution for a Tenants Association impacts upon the tenants' lived realities and can become a vehicle for social change. The mediators are also trained to check the influence of their disciplines (law and social work), and their own relationships to poverty, social housing, gender, and older adults. The mediators' personal and professional commitments to social justice also encouraged them to think beyond their more obvious role to examine the underlying causes of the conflict, to note the homogeneous nature of the Tenants Association Executive, and to actively engage unrepresented tenants in the process. This commitment to cultural competence required the mediators to do more than simply facilitate the mediation process as it was presented to them: it required them to examine the problem through a culturally competent lens and to make visible the struc-

12 This approach was informed by Trina Grillo's work on the sexist cultural practice that stifles women's ability to express anger. See Trina Grillo, "The Mediation Alternative: Process Dangers for Women" (1991) 100 Yale L.J. 1545. 
tural and systemic discrimination that had remained invisible to some of the actors in the process. The Tenants Association example thus demonstrates how ADR can create spaces for empowerment and social transformation.

\section{CRITIQUES OF ADR}

But, just as ADR processes have the potential to empower and transform, ADR can also provide space for undermining or simply ignoring social justice concerns. Owen Fiss's article "Against Settlement" encapsulates many of the critiques expressed by those who worry about ADR undermining substantive legal norms and processes. ${ }^{13}$ Fiss helped build the foundation for ADR oppositionists who argue that private settlement deprives courts of the opportunity to set public standards of right and wrong and to interpret legislation and court decisions. As Fiss wrote, " $[\mathrm{t}]_{\mathrm{o}}$ be against settlement is only to suggest that when the parties settle, society gets less than what appears, and for a price it does not know it is paying. Parties might settle while leaving justice undone." 14 Social justice advocates have also argued that informal settlement processes undermine formal human rights protections; feminists, for example, provide alarming examples of mediations which perpetuated inequality and, in some cases, abuse. ${ }^{15}$ In mediation clinics, generally staffed by activists and social progressives, the result may be no better. In studies of community justice centres in the United States, Professor Sally Engle Merry questioned whether the rights of vulnerable citizens could be trampled upon in a process without formal legal protections. ${ }^{16}$ She posed important social policy questions: "Should we interpret the expansion of ADR as the development of a more responsive, humane justice system or as another aspect of the elimination of state social services for the poor? Is this a move toward better justice or cheaper justice?"17 As Professor Merry found, private settlement might deprive those who lack social power the protections afforded by an adjudicative process, leaving them with an inferior and unreviewable result.

1393 Yale L. J. 1073 (1984).

14 Ibid. n. 8.

15 See especially Trina Grillo, “The Mediation Alternative: Process Dangers for Women” (1991) 100 Yale L.J. 1545; Carol M. Rose, “Bargaining and Gender” (1995) 18 Harv. J.L \& Pub. Pol'y. 547; and Carol M. Rose, "Women and Property: Gaining and Losing Ground" (1992) 78 Va. L. Rev. 421; Penelope E. Bryan, "Killing Us Softly: Divorce Mediation and the Policies of Power" (1992) 40 Buff. L. Rev. 411; Laura Nader, "Controlling Process in the Practice of Law: Hierarchy and Pacification in the Movement to Reform Dispute Ideology" (Fall 1993) 9:1 Ohio St. J. Disp. Resol. 1. Deborah Kolb \& Kathleen McGinn, "Beyond Gender and Negotiation to Gendered Negotiation” (29 October 2008) Harvard Business School NOM Working Paper No. 09-064, online: SSRN <http://ssrn.com/abstract=1291948>.

16 Professor Sally Engle Merry tells the story of an older adult woman whose neighbour interrupted her daily living because he was building a boat in his driveway into the evening hours. In the mediation that occurred over the issue, the younger, louder male neighbour insisted on continuing to build the boat and the older woman acquiesced despite the fact that there was a municipal noise by-law prohibiting such noise in the evenings. See Sally Engle Merry \& Neil Milner, eds., Sally Engle Merry \& Neil Milner, eds., The Possibility of Popular Justice: A Case Study of American Community Mediator (Ann Arbor: University of Michigan Press, 1993).

17 Ibid. 
This opposition to informal dispute resolution processes, particularly mediation, has also found a voice in the legal profession. Lawyers have framed their opposition to settlement processes in a variety of ways, ${ }^{18}$ but certainly one that deserves further exploration is fear that clients who are already marginalized might face further discrimination in a private dispute resolution process. ${ }^{19}$

These fears ${ }^{20}$ reflect scepticism that the "promise of mediation" 21 can deliver such benefits as party self determination, empathy, education, relationship improvement, and prevention of future harm while at the same time upholding human rights and social justice principles. ${ }^{22}$ For example, Trina Grillo argued that social inequality was reified through a mediation process; ${ }^{23}$ this in stark contrast to the claim that mediation was a more "feminine" or "woman-friendly" process because it eschewed adversarial methods. The juxtaposition of these competing claims obscures the possibility that mediation and other informal dispute resolution processes can deliver on their 'promises' and incorporate notions of equality and justice. I argue that mediation does not have to involve a trade-off between negotiation and human rights. In short, accepting mediation as a dispute resolution process does not entail ignoring substantive norms or outcomes or giving up on social justice and human rights for the sake of compromise. On the contrary, mediation can generate social justice and entrench human rights in the day to day lives of those who engage in it. This paper provides some suggestions for improving the social justice integrity of mediation, but also argues we must go beyond these measures to strengthen social justice both in process and outcome. In doing so, settlement processes have the potential not only to ensure increased protections for marginalized populations, they may also increase the quality of discourse around the role of human rights in the day-to-day lives of citizens, thereby strengthening and deepening the role of human rights, cul-

18 For a description of a variety of reactions to mandatory mediation in a civil context - from the "oppositionist" to the "true believer" see Julie Macfarlane, "Culture Change? Commercial Litigators and the Ontario Mandatory Mediation Program” (2001) (Ottawa: Law Commission of Canada), online: Dalhousie University <https://dspace.dal.ca/dspace/items-by-author?author $=$ Macfarlane $\% 2 \mathrm{C}+$ Julie $>$.

19 In fact, one student who had taken several ADR classes in law school stated that when she suggested mediation in a human rights case, the lawyer stated he "never mediated" because it deprives him of the opportunity to set precedent. Of note is the proprietary nature of the lawyer's statement.

20 Professor Voyvodic was among those who expressed concern in the early days of mediation projects in Windsor, Ontario that ADR may not provide adequate protection for marginalized populations.

21 Robert A. Baruch Bush \& Joseph P. Folger in The Promise of Mediation: the Transformative Approach to Conflict (San Francisco, Jossey-Bass 1994) proposed that mediation could provide party empowerment through a process of moral growth and recognition through a transformative mediation approach.

22 Other authors who argued these positive effects followed from mediation include; Leonard Riskin, "Mediation and Lawyers" 43 Ohio St. L.J. 29; Tom R. Tyler, "The Quality of Dispute Resolution Processes and Outcome: Measurement Problems and Possibilities" 55 Denv. U.L. Rev.419; Craig McEwen, "Note on Mediation Research" in Stephen E. Goldberg et al., eds., Dispute Resolution: Negotiation, Mediation, and Other Processes, 5th ed. (Chicago: Wolters Kluwer, 2007) at 156-158.

23 Supra note 15. 
tural competence and social justice in Canadian society. The first step towards improving the social justice integrity of mediation involves injecting the norms of cultural competence into the practice of mediation through a re-thinking of codes of conduct.

\section{CURRENT REGULATORY MODELS}

There is no single governing body for mediators, facilitators, or other ADR practitioners. Most mediators and arbitrators voluntarily register as members of a particular organization which binds its members to a code of conduct. ${ }^{24}$ In Canada, for example, the ADR Institute of Canada has its own Code of Ethics ${ }^{25}$ and Model Code of Conduct for Mediators, ${ }^{26}$ as does Family Mediation Canada. ${ }^{27}$ Mediation rosters such as the Ontario Mandatory Mediation Program ${ }^{28}$ generally have their own Codes of Conduct. In British Columbia, all rosters of the British Columbia Mediator Roster Society including civil, family, and the B.C. Child Protection Mediation Program roster are bound by one Standard of Conduct. ${ }^{29}$

While there are many ethical codes, most contain very similar provisions. In most cases, the provisions focus on regulation through formal procedures. For example, all codes bar bias and conflicts of interest in order to maintain mediator impartiality; all also contain a confidentiality provision. Other common elements include guidelines on the use of terms of mediation, limitations on advertising, and guarantees of mediator competence. ${ }^{30}$

To the extent possible, mediators often bind themselves and the parties to particular procedures through a document signed before mediation begins, usually referred to as "an Agreement to Mediate" or "the Terms of Mediation." Whether the terms of these documents can be enforced remains somewhat ambiguous; regardless, the terms generally bear little difference to the contents of ethical codes. ${ }^{31}$

Thus far, case law does not prescribe mediators to follow a particular ethical path. The majority of case law speaks to procedural issues such as limits on con-

24 There are also mediators, facilitators, arbitrators and trainers who do not register with any particular agency or organization and as such are not formally bound by any regulations outside the law.

25 ADR Institute of Canada, online: ADR Institute of Canada <http://www.adrcanada.ca/rules/ code_of_ethics.pdf $>$.

26 ADR Institute of Canada, online: ADR Institute of Canada <http://www.adrcanada.ca/rules/ national_code_of_conduct.pdf >.

27 Family Mediation Canada, Code of Professional Conduct, online: Family Mediation Canada $<$ http://www.fmc.ca/pdf/CodeProfessionalConduct.pdf $>$.

28 Ministry of the Attorney General, Ontario Mandatory Mediation Program, Code of Conduct, online: Ministry of the Attorney General <http://www.attorneygeneral.jus.gov.on.ca/english/ courts/manmed/codeofconduct.asp >.

29 British Columbia Mediator Roster Society (2007), online: British Columbia Mediator Roster Society <http://www.mediator-roster.bc.ca/Standards_Conduct.pdf>.

30 See supra notes 25, 26 and 27.

31 Presumably, if a mediator is a member of an ADR organization he or she must follow the edicts of that organization's codes; therefore, terms of mediation for private mediators should mirror their ethical codes. 
fidentiality and ability to subpoena the mediator rather than more substantive justice issues. Baker v. Zurich Canada, ${ }^{32}$ for example, held that a confidentiality clause was an implied term of the mediation process; Rudd v. Trussacs Investments $^{33}$ dealt with the issue of whether mediators should be called to testify in certain cases; and Rogacki v. Belz ${ }^{34}$ also dealt with the parameters of confidentiality in mediation. Thus, the courts have not made inroads into requiring positive guarantees of culturally competent or socially just mediation practices. ${ }^{35}$

\section{EXCEPTIONS}

A few ethical codes relevant to ADR practices mention issues of social justice, protection of marginalized populations, cultural competence or human rights. Some frame their social justice commitments as negative obligations, such as the British Columbia Mediator Roster Society's Standards of Conduct which states "a family mediator must ensure that he or she has specialized knowledge and procedural skills sufficient to properly identify and manage cases involving vulnerable participants, abuse, or a power imbalance between participants." ${ }^{36}$ This particular Code also notes the importance of assessing whether a particular dispute is appropriate for mediation through a screening and interview process that identifies whether abuse has occurred..$^{37}$ Mediators are also instructed to end the mediation process if the process "is likely to harm or prejudice one of the participants." ${ }^{38}$ This is the only positive duty noted for mediators that requires specific inquiry into abuse, and is only applicable in certain types of cases involving family mediation.

The American Bar Association's Model Standards of Conduct for Mediators also mentions circumstances involving domestic abuse or violence. ${ }^{39}$ Standard VI states that "[i]f a mediator is made aware of domestic abuse or violence among the parties, the mediator shall take appropriate steps, including, if necessary, postponing the mediation, withdrawing from, or terminating the mediation." ${ }^{40}$ While an interesting (but not very instructive) standard, the ABA's Code contains no more general commitment to social justice principles. Family Mediation Canada is similarly silent about mediators ensuring that they pursue social justice principles. In its definition of "family mediation," Family Mediation Canada's Members Code of Professional Conduct acknowledges the diversity of modern familial relations but again makes no other specific or general comment about social justice principles. ${ }^{41}$

32 (2003) 68 OR (3d) 350.

33 (2004) 244 DLR (4th) 758.

34 (2003) 232 DLR 4th 523 (C.A.).

35 In all likelihood, the courts are not the best body to rule on issues of social justice and cultural competency in mediation, save for perhaps cases involving unconscionable contracts.

36 Supra note 28 at 2.

37 Ibid.

38 Ibid.

39 ABA, Model Standards of Conduct for Mediators, (2005) online: American Bar Association $<$ http://www.abanet.org/dispute/documents/model_standards_conduct_april2007.pdf>.

40 Ibid.

41 Supra note 26. 
There is no mention of cultural competence in any of the Codes surveyed, nor are there general commitments to a value-based approach that includes social justice standards. Like ethical codes for lawyers, nearly all mediation codes focus on process rather than positive statements regarding social justice or cultural competence. Further, when there is mention of protection of vulnerable populations, it seems that domestic violence is the marker of inequality. ${ }^{42}$

\section{THE CANADIAN ASSOCIATION OF SOCIAL WORK, SOCIAL JUS- TICE \& CULTURAL COMPETENCE}

While this paper deals mostly with ethical codes, it is important to note the shortfalls of relying solely on this prescriptive method. Mediation, like most professional practice, involves complex decisions that no ethical code can capture accurately. ${ }^{43}$ However, ethical codes can function to guide complex decisions and set out professional norms. While current procedure-based codes assist in setting out general parameters of the process, they do not assist with substantive social justice issues in the same way as other professions: notably social work. ${ }^{44}$ The Canadian Association of Social Workers' (CASW) Code of Ethics ${ }^{45}$ and accompanying Guidelines ${ }^{46}$ provides a useful model for implementing both cultural competence and social justice standards in a profession with great diversity of practice. ${ }^{47}$ This Code proves useful in the mediation context because of the many similarities that mark the roles of ADR professionals and social workers, includ-

42 One may presume this is in response to feminist critiques of family mediation from the mid- to late 1990s. See supra note 15 for sources.

43 Catherine Morris notes,

[c] odes of ethics typically provide a prescriptive list of dos and don'ts which rarely fit the particulars of an ethical quandary... and tend... to treat the situation as though ethical problems in the dispute were the exclusive responsibility of the mediator to resolve... independently of the parties... Codes of ethics usually do not detail the ethical values on which they are founded... [a]nd give the illusion that the organizations of mediators who created them have reached a unified consensus about mediation practice.

"The Trusted Mediator : Ethics and Interaction in Mediation" in Julie Macfarlane, ed., Rethinking

Disputes : the Mediation Alternative (Toronto: Emond Montgomery, 1997) at 301.

Julie Macfarlane also notes problems with implementing ethical codes in mediation.

The exercise of... broad discretion [in mediation] often comes down to on-the-spot judgements made as the dialogue unfolds, reflecting instinctive preferences over style and strategy... Aside from egregious process abuse or party misconduct, the mediator's judgments are often invisible to the parties themselves.

"Mediating Ethically: the Limits of Codes of Conduct and the Potential of a Reflective Practice Model" (2002) 39(4) Osgoode Hall L.J. 49.

44 This is not to suggest that the field of ADR has not battled with issues of inequality and social justice, but rather that these critiques and debates have not found their way into ethical codes.

45 Canadian Association of Social Workers (CASW), Code of Ethics, 2005.

46 Canadian Association of Social Workers (CASW), Guidelines, 2005.

47 It is important to note that despite social work's value commitment to social justice, some argue that the Code does not go far enough. Bob Mullaly, for example, argues that the 2005 Code is much more ambiguous than its predecessor in its stance on issues of social justice; specifically, it does not set out a definitive vision of what the social work profession stands for. See The New Structural Social Work: Ideology, Theory, Practice, 3d ed. (New York: Oxford University Press, 2006). 
ing the emphasis on self-determination and confidentiality for clients, and the diversity in approaches and services provided by social workers and mediators. Social workers practice in widely diverse areas; including education, policy and administrative work, community development, individual therapy, community organizing, and advocacy. They use a variety of approaches some of which echo mediation approaches including transformative and narrative interventions. Some therapy - like evaluative and some facilitative practice - is clearly solutionfocused or 'problem solving' in nature. ${ }^{48}$ Conversely, transformative practices in social work and mediation explicitly avoid focusing on solutions and problemsolving. ${ }^{49}$ For transformative practitioners, the goals of party empowerment and mutual recognition can be impeded by a focus on problem-solving. ${ }^{50}$ Despite this diversity of practice, social work emphasizes very specific statements about social justice in its codes of ethics. ${ }^{51}$

The CASW Code of Ethics is much more definitive than ADR Codes in its commitment to social justice, providing concrete procedural and substantive commitments. For example, listed as the second social work Value, the "Principles of the Pursuit of Social Justice" 52 are:

- Social workers uphold the right of people to have access to resources to meet basic human needs.

- Social workers advocate for fair and equitable access to public services and benefits.

- Social workers advocate for equal treatment and protection under the law and challenge injustices, especially injustices that affect the vulnerable and disadvantaged.

- Social workers promote social development and environmental management in the interests of all people. ${ }^{53}$

The CASW Code commits to ensuring basic human rights are met and that; achieving equality - particularly for individuals marginalized by injustice - is a positive duty. The Code makes very overt commitments to specific social justice principles with ideals very similar to human rights law. Interestingly, these particular sections deal not with social justice framed through an individualist lens, but one which emphasizes equality for "all people," therefore avoiding liberal notions of the individual pitted against the wider society.

The duty to "challenge injustice" can only be perceived as problematic

48 See especially Scott Miller, et al., Handbook of Solution Focused Therapy (San Francisco: JosseyBass, 1996).

49 See, in social work, Rhea Almeida et al., Transformative Family Therapy (Boston: Allyn and Bacon, 2007). For a mediation approach that draws upon social work concepts of narrative therapy, see John Winslade \& Gerald Munk, Narrative Mediation (San Francisco: Jossey-Bass, 2000). The transformative approach to mediation was discussed above.

50 See especially Bush \& Folger, The Promise of Mediation, supra note 21.

51 This is not to say that social work and mediation have the same purposes, functions, capabilities or strategies.

52 Supra note 7 at 5.

53 Ibid. 
through the lens of the mediator as neutral. ADR theorists have debated the issue of mediator as "neutral" versus mediator as "impartial third party." 54 The difference between these terms is important from a social justice perspective. ${ }^{55}$ Neutrality assumes a value free actor. Impartiality, by contrast, assumes a commitment to equality and action. Marc Weller uses an effective example illustrating the difference in action:

In the context of humanitarian action... neutrality is a principle of abstention. A third party to a conflict must not undertake (or possibly permit) activities which would assist the war effort of either party to a conflict. ... [I]mpartiality is defined as a principle of action. Whatever humanitarian action is being undertaken... must be administered in accordance with an objective standard which is applied equally to all parties. ${ }^{56}$

Thus, a strict 'neutral' will be less likely than an 'impartial' to intervene to encourage a quiet party to speak. Although the term 'neutral' is often used in reference to mediators, most organizations have changed the language of their ethical codes to refer to "impartiality," ${ }^{57}$ although impartiality is not always clearly defined. This change reflects and makes way for the more positive role of ADR professionals in providing socially just services, and must be considered a necessary change to ADR ethical codes. ${ }^{58}$

\section{CASW \& CULTURE, DIVERSITY \& CULTURAL COMPETENCE}

The CASW Code also makes concrete commitments to human rights and diversity. These commitments are contained throughout the Code, but a few statements demonstrate the systemic way they are articulated. The first Value in the Code, "Respect for Inherent Dignity of Persons" stresses the importance of differences and distinct belief systems. It reads

54 Hilary Astor, "Rethinking Neutrality: A Theory to Inform Practice - Part I" (2000) 11:2 Australasian Dispute Resolution Journal 73; Hilary Astor, "Rethinking Neutrality: A Theory to Inform Practice - Part II” (2000) 11:3 Australasian Dispute Resolution Journal 145; Sara Cobb \& Janet Rifkin, "Practice and Paradox: Deconstructing Neutrality in Mediation" (1991) 16:1 Law \& Soc. Inquiry 35; Janet Rifkin, Sara Cobb \& Jonathan Millen, "Toward a New Discourse for Mediation: A Critique of Neutrality” (1991) 9:1 Mediation Quarterly 151.

55 Marc Weller, “The Relativity of Humanitarian Neutrality and Impartiality” (28 February 1998) Journal of Humanitarian Assistance, online: Journal of Humanitarian Assistance <http://jha. ac/1998/02/28/the-relativity-of-humanitarian-neutrality-and-impartiality/>.

56 Ibid.

57 Ethical codes that use the term "impartial" include the Ontario ADR Section's Model Code of Conduct for Mediators, supra note 25; the Ontario Association for Family Mediator's Code of Ethics for Child Protection, supra note 26; the British Columbia Mediator Roster Society's Standards of Conduct, supra note 28; Family Mediation Canada's Members Code of Professional Conduct, online: Family Mediation Canada' <http://www.fmc.ca/pdf/CodeProfessionalConduct.pdf> and the Landlord and Tenant Board's Code of Ethics and Professional Responsibility, (2006), online: Landlord and Tenant Board <http://www.ltb.gov.on.ca/en/About_Us/STEL02_111391.html>.

58 This distinction between impartiality and neutrality is echoed in Justice Bertha Wilson, "Will Women Judges Make a Difference?” (1990) 28:3 Osgoode Hall L.J. 507. 
Social workers respect the diversity of individuals in Canadian society and the right of individuals to their unique beliefs consistent with the rights of others. ... Social workers respect the distinct systems of beliefs and lifestyles of individuals, families, groups, communities and nations without prejudice. $^{59}$

The Code sets out a positive duty to combat discrimination in language that echoes human rights standards. Under "Pursuit of Social Justice," the Code reads: "[s] ocial workers oppose prejudice and discrimination against any person or group of persons, on any grounds, and specifically challenge views and actions which stereotype particular persons or groups." ${ }^{60}$ Significantly, the Code does not frame diversity needs through the lens of cultural competence, but does reference the knowledge and attitudes required by Professor Voyvodic in her requirements for culturally competent legal practice. ${ }^{61}$

\section{IN PRACTICE}

While ethical commitments to social justice and cultural competence may be difficult for mediators to practice, they are necessary for public confidence in the process and for full participation of all parties. The primary theoretical difficulties for mediators lie in the fact that value commitments are often confused with partiality. But good mediation can address differences in values between the parties without shading into impartiality. For example, in another dispute mediated through Mediation Services, a Pakistani, Muslim male in his early twenties wished to sue his neighbour for erecting surveillance cameras that pointed onto the family's property. While he attended the intake at Mediation Services, it became clear that his mother, two brothers and sister were living in Canada with few support networks. The son was charged with taking care of the family business. During the mediation, the mediators learned that the neighbour, a single mom, was upset about the children walking on her lawn and had erected the cameras (which actually were never activated) to scare her neighbours away. After significant discussion, the root cause of this seemingly extreme reaction became clear. It was explained through the single mother's dislike of the mother's and daughter's less dominant role in the family. She had experienced abuse in her former relationship and had strong liberal feminist views about the role of women in families. She very vocally objected to the fact that the daughter did not go out alone. This potentially volatile exchange engaged the parties in an extensive explanation of Pakistani, Muslim culture, roles of women in both cultures, and storytelling about both families' troubled histories. Likewise, the young man had been told that Canadians deal with disputes by suing one another so he adopted an adversarial stance out of the conviction that this was what was required of him. The parties engaged in further discussion about the need for open communication when disputes arose between them and came to 
understand each other better through their differences (including the importance of an immaculate lawn for some Canadians). The ability to see past a lawn and address the core cultural values at play not only illustrates the importance of cultural competence in mediation, it also demonstrates that encouraging discussion about culture where one party may be perceived as 'dominant' does not offend notions of impartiality.

Additionally, social justice commitments do not compromise any particular mediation practice model. An evaluative mediator may reference positive commitments to human rights or a likely outcome of filing for a peace bond without compromising trust or impartiality. In fact, ethical commitments to social justice may accomplish exactly the transformative ends envisioned by some mediation advocates. The greater practice challenge lies in the fact that both (or all) parties may be together in the mediation room and therefore stopping or correcting a party may be perceived as biased or partial, even silencing. However, the way the mediator interjects holds great potential for educative rather than corrective, and potentially paternalistic, practice. For example, the mediator may simply stop and/or admonish a party who utters an anti-immigrant comment. But prohibiting or preventing such comments can be done in creative rather than purely prescriptive ways. Such comments could in fact lead to a discussion about human rights, social justice, or cultural competence as they did in the dispute between neighbours noted above. There are additional ways a mediator might engage in anti-oppressive practice. Mediators often establish 'ground rules' at the beginning of mediation that set out expectations of appropriate behaviour. A clear statement about racism, sexism, and homophobia, for example, often sets a tone for the mediation. A commitment to social justice also means that the mediator would have a positive obligation to include a statement in her terms of mediation or other contracting document before mediation begins, include it in her opening statements, and reinforce it throughout the process. At the same time, expressing such beliefs sometimes provides an opportunity for parties to discuss underlying attitudes that may be the source of their conflict. A culturally competent mediator may facilitate such a discussion in a manner that allows the parties to feel safe, heard, and respected. Mediation may also allow competing rights claims to face and come to terms with one another. As the Universal Declaration of Human Rights states, human rights protections are interrelated, interdependent and indivisible, ${ }^{62}$ and of course abut one another, sometimes with results that cause or exacerbate human conflict. Instead of framing these rights as competing, it is possible through a resolution process to frame them as mutually reinforcing, collaborating, or at least peacefully co-existing.

\section{BEYOND CODES}

While this paper focuses on ethical codes as one way to promote cultural competence and social justice, there are clearly more substantive means that must go

62 Universal Declaration of Human Rights, United Nations Department of Public Information, 1948, online: United Nations Human Rights <http://www.unhchr.ch/udhr/lang/eng.htm>. This notion has been reaffirmed in many UN documents since. 
hand-in-hand with regulation. No code can teach mediators how to carefully but definitively respect human rights and social justice, nor can a code adequately explore the impact of systemic inequality. Therefore, conflict resolution education must include a social justice component. ${ }^{63}$ Preferably, a social justice approach should be taken throughout training to ensure a more thorough and overarching integration of cultural sensitivity and social justice in conflict resolution. Groups governing the regulation of mediators and arbitrators should include mandatory training on culture, cultural competence, social justice, and anti-oppressive practices. Without a solid grounding in the theory and practice of anti-oppression, mediators simply may not be cognizant of the effects of their practice.

One of the primary ways of assessing concerns about cultural competence and social justice in a mediation context is through intake. As with many professions, mediators may hold a formal intake in person or over the phone before mediation occurs; others rely on mediation briefs or other written documents. Most mediators use the intake to assess likelihood of settlement; however, the intake could be more valuable in a social justice context, particularly in assessing any social justice concerns, discussing the role of cultural competence and social justice in mediation, and setting the framework for the mediator's role. Reexamining the role of intake and of dispute resolution education are only two of many other ways to strengthen social justice and cultural competence in ADR; but without formal commitments recognizing the importance of social justice in $\mathrm{ADR}$, it is unlikely to be encouraged on a widespread and systemic basis.

\section{RIGHTS TALK V. STORYTELLING?}

Windsor Mediation Services examples cited above illustrate how a mediation process can become a site of discourse around social justice and human rights, and one with enormous potential. The clear tendency in human rights and social justice discourse is rules and rights-based reasoning that becomes more problematic in action, particularly when values and rights compete. For example, the neighbourhood example above might be framed as a discourse around rights - the rights of women versus religious freedom. This distributive vision of rightstalk has the potential for party empowerment, but in this case, it led to destructive and mutually abusive practices with each side adopting an adversarial stance against the other. Framing the issue as one of individual and integrated stories, with rights forming an important backdrop, is far more likely to lead to mutual understanding and, ultimately, reconciliation of rights-in-action. The parties came to appreciate the rights of the others by first appreciating their shared stories of fear and disappointment. In this way, the challenge of understanding rights on a very practical and human level could at least be discussed at one of the most basic sites of discourse. Mediation may provide a forum by which the grassroots discussions of the complex interplay of human rights and conflict can find expression. In this way, the 'transformative' goals of mediation lie in the potential to expand our notions of what human rights mean in action.

63 While this may seem self-evident, most training and training policy focuses on procedural matters such as the mediation process and communication skills and ignores issues of inequality. 


\section{CONCLUSION}

In choosing their ethical paths, $\mathrm{ADR}$ organizations have chosen to follow more closely in the path of law, which does not make any explicit commitment to social justice in its ethical codes, rather than following social work, which makes clear formal and substantive commitments to social justice. But ADR ethical codes must begin by formally cementing the place of informal processes as equitable - not just efficient - options for settlement. Along with substantive measures including revitalized commitments to social justice education in dispute resolution, stronger intake measures, and re-imagined means of designing dispute resolution systems, ADR-particularly mediation- can provide sites of discourse around the very fundamental and practical ways human rights and social justice play out in citizens' daily lives. 